\title{
Association between CMD signs and symptoms, oral parafunctions, race and sex, in 4-6-year-old African- American and Caucasian children
}

\author{
S.E. WIDMALM, * S.M. GUNN, ${ }^{\dagger}$ R.L. CHRISTIANSEN ${ }^{\dagger} \&$ L.M. HAWLEY ${ }^{\dagger}{ }^{*}$ Department of \\ Cariology and General Dentistry, and Department of Orthodontics, University of Michigan School of Dentistry, Ann Arbor, Michigan, U.S.A.
}

\begin{abstract}
SUMmaRy The associations between oral parafunctions, signs and symptoms of craniomandibular disorders (CMD), race, and sex were analysed in recordings from 203 4-6-year-old African-American and Caucasian children. Significant correlations were found between bruxism, nail biting, thumb sucking and most of the CMD signs and symptoms. There were also significant associations between most of the signs and symptoms and race, while significant association with sex was found only regarding headache, TMJ sounds and chewing pain. Significant associations were found between most CMD signs and TMJ sounds supporting the view that joint sound
\end{abstract}

recordings have diagnostic value. There were also significant associations between the pain variables recorded by questionnaire and those recorded by palpation, which indicates that reliable data can be obtained by interviewing children as young as five. The results of this study support the concept that oral parafunctions have a significant role in the aetiology of CMD. The results also show that race and sex need to be considered when analysing the possible aetiological role of oral parafunctions in CMD. Longitudinal studies, beginning with low age groups are needed to better determine the role of childhood oral parafunctions in CMD aetiology.

\section{Introduction}

The aetiology of craniomandibular disorders (CMD) is generally agreed to be multifactorial (Ash, 1986) with oral parafunction playing a significant role. Epidemiological studies have found associations between oral parafunctions, signs and symptoms of CMD and gender (Helkimo, 1979; Egermark-Eriksson, 1982a,b; Nilner, 1983; Westling, 1988; Kleinrock et al., 1990). Little is known, however, about the strength of association between the various parafunctions, various CMD signs and symptoms, and gender. These complex interactions are partly known (Wechsler, 1931; Backlund, 1963; Ayer, 1979; Nilner, 1983), but few studies have recorded those associations in children below 7 years of age.

The role of sociomedical and socio-economic factors in the aetiology of $\mathrm{CMD}$ has been recognized and addressed by several authors (Franks, 1964; Helöe, Helöe, 8 Heiberg, 1977; Nilner \& Lassing, 1981; EgermarkEriksson, 1982a; Thilander, 1986; Gunn, Woolfolk \& Faja, 1988) but less often concerning the question of possible racial differences. This may be because most epidemiological studies have been made in areas where almost the entire population have belonged to the same racial group. More studies are therefore needed to clarify the role of, and interaction between, socio-economic, gender and racial factors.

The aims of the present study were to examine the association between oral parafunctions, race, gender and CMD signs and symptoms; to examine the association and relationships between various signs and symptoms of CMD in 4-6-year-old children; and to test the hypothesis that parafunctions are significant factors in the aetiology of CMD.

\section{Methods}

Examinations were performed on 203 children, 153 Caucasian ( 88 boys and 65 girls) and 50 African-American ( 25 boys and 25 girls), mean age $5.06 \pm 0.634$ (s.d.), from a pre-school and kindergarten, 20 miles west of Detroit, Michigan. 
The children were interviewed concerning TMJ pain, headache, earache, neck pair, chewing pain, problems in jaw opening, ear noise during jaw movements, and oral parafunctions (bruxism, nail biting and thumb/finger sucking). They were examined for pain by palpation of lateral and posterior TMJ, temporal and masseter areas, for jaw function (range of opening and lateral movements, deviations in the coronal plane) and for TMJ sounds (for details see Widmalm et al., 1995).

\section{Statistical analysis}

Associations between variables were examined using Cramér's V (SPSSPC + statistical package) where the statistic is a chi-square based measure of association that can attain values between 0 and 1 for tables of any dimension. 0 corresponds to no association and 1 to perfect association. The values were calculated using the formula: $V=\sqrt{\chi^{2} / N(k-1)}$, where $k$ is the smaller of the number of rows and columns, $N=$ number of observations and $\chi^{2}=$ the Pearson chi-square statistic.

Tests of statistical significance do not measure the strength of relationship between variables. They can only show if such a relationship does exist. Measures of association reflect both the strength and the nature of the relationships in one single summary statistic. Among the tests available, Cramér's $V$ is considered to be the most versatile for nominal and ordinal data and categorical variables are usually interpreted in the following way (Rea G Parker, 1992):

0.00 and under $0.10 \quad$ Negligible association.

$0 \cdot 10$ and under $0 \cdot 20 \quad$ Weak association.

0.20 and under $0.40 \quad$ Moderate association.

0.40 and under 0.60 Relatively strong association.

0.60 and under $0.80 \quad$ Strong association.

0.80 to $1.00 \quad$ Very strong association.

None of the values in this study were greater than 0.60 . Cramér's V rarely achieves a value of 0.80 or above (Poister, 1978).

\section{Results}

Complete results are presented in Tables $1-4$, some of which are repeated here with the value of the Cramér's $V$ statistic in parenthesis. $\mathrm{CMD}=$ craniomandibular disorder.
Association between oral parafunctions and signs and symptoms of $C M D$

Bruxism was significantly associated with 11 of the 15 recorded CMD variables: TMJ pain $(0 \cdot 20)$; headache $(0 \cdot 25)$; earache $(0 \cdot 26)$; neck pain $(0 \cdot 41)$; chewing pain $(0 \cdot 27)$; pain at jaw opening movement $(0 \cdot 32)$; palpation pain in the lateral TMJ $(0 \cdot 22)$; posterior TMJ $(0 \cdot 15)$ and masseter areas (0.30); problems in jaw opening $(0 \cdot 30)$; and ear noise $(0 \cdot 20)$.

Nail biting was significantly associated with eight of the 15 recorded $C M D$ variables: headache $(0 \cdot 19)$; neck pain $(0 \cdot 24)$; chewing pain $(0 \cdot 21)$; pain at jaw opening movement (0-18); palpation pain in the lateral TM. $(0 \cdot 18)$ : posterior TMJ $(0 \cdot 24)$ and in the masseter $(0 \cdot 22)$ areas; and with problems in jaw opening $(0 \cdot 17)$.

Thumb or finger sucking was significantly associated with seven of the 15 recorded CMD variables: headache $(0 \cdot 20)$; neck pain $(0 \cdot 18)$; chewing pain $(0 \cdot 24)$; pain at jaw opening movement $(0 \cdot 20)$; palpation pain in the lateral TMJ (0.26); posterior TMJ (0.19); and in the masseter areas $(0 \cdot 25)$.

Association between race, sex and signs and symptoms of $C M D$

Race was significantly associated with 10 of the $15 \mathrm{CMD}$ variables: TMJ pain $(0 \cdot 21)$; neck pain $(0 \cdot 18)$; chewing pain (0.33); pain at jaw opening movement $(0 \cdot 26)$; palpation pain in the lateral TMJ $(0 \cdot 18)$; in the posterior TMJ (0.20); in the masseter $(0.21)$; and in the temporalis area $(0 \cdot 18)$; ear noise $(0 \cdot 21)$; and TMJ sounds $(0 \cdot 23)$.

Sex was significantly associated with three of the 15 CMD variables: headache $(0 \cdot 25)$; chewing pain $(0 \cdot 14)$; and TMJ sounds $(0 \cdot 16)$.

Association between TMJ sounds and other signs and symptoms of CMD

There were significant associations between ear noise (Table 3), as recorded by interviewing the children, and six of the 14 other recorded CMD signs and symptoms: history of TMJ (0.27) and of neck pain $(0 \cdot 22)$; chewing pain $(0 \cdot 24)$; pain at jaw opening $(0 \cdot 20)$; palpation pain in the lateral TMJ $(0 \cdot 20)$; and in the masseter area $(0 \cdot 23)$.

There were significant associations between TMJ sounds, as recorded by auscultation, and eight of the 14 other recorded CMD signs and symptoms: history of earache (0.18); pain at jaw opening $(0 \cdot 16)$; palpation tenderness of the lateral TMJ $(0 \cdot 30)$; the posterior TMJ $(0 \cdot 30)$; 
Table 1. Association between oral parafunctions and pain and dysfunction signs and symptoms

\begin{tabular}{|c|c|c|c|}
\hline & Bruxism & Nail biting & Thumb/finger sucking \\
\hline \multicolumn{4}{|l|}{ Pain history } \\
\hline TMJ pain & $0 \cdot 20^{*}(3)$ & 0.12 n.s. & 0.07 n.s. (1) \\
\hline Headache & $0 \cdot 25^{\star \star}(3)$ & $0 \cdot 19^{\star}$ & $0 \cdot 20^{\star}(1)$ \\
\hline Earache & $0 \cdot 26^{\text {** }}(4)$ & 0.16 n.s. (1) & $0 \cdot 15$ n.s. (2) \\
\hline Neck pain & $0.41^{* * *}(3)$ & $0 \cdot 24^{* \star}$ & $0 \cdot 18^{*}(1)$ \\
\hline \multicolumn{4}{|l|}{ Pain at function } \\
\hline Chewing & $0 \cdot 27^{* * *}(5)$ & $0 \cdot 21^{* *}(2)$ & $0 \cdot 24^{* * *}(3)$ \\
\hline Jaw opening movement & $0 \cdot 32^{* * *}(3)$ & $0 \cdot 18^{\star}$ & $0 \cdot 20^{\star \star}(1)$ \\
\hline \multicolumn{4}{|l|}{ Pain at palpation } \\
\hline Lateral TMJ & $0 \cdot 22^{* *}(3)$ & $0 \cdot 18^{\star \star}$ & $0 \cdot 26^{\star * \star *}(1)$ \\
\hline Posterior TMJ & $0 \cdot 15^{*}(3)$ & $0 \cdot 24^{* \star \star}$ & $0 \cdot 19^{\star \star}(1)$ \\
\hline Masseter & $0 \cdot 30^{* * *}(3)$ & $0 \cdot 22^{* *}$ & $0 \cdot 25^{* * *}(1)$ \\
\hline Temporalis & 0.07 n.s. (3) & 0.08 n.s. & 0.04 n.s. (1) \\
\hline \multicolumn{4}{|l|}{ Jaw movement dysfunction } \\
\hline Problems in jaw opening & $0 \cdot 30^{* * *}(3)$ & $0 \cdot 17^{\star}(1)$ & 0.12 n.s. (2) \\
\hline Deviation at jaw opening & 0.07 n.s. (3) & 0.07 n.s. & 0.01 n.s. (1) \\
\hline Reduced jaw opening degree & 0.02 n.s. (3) & 0.13 n.s. & 0.05 n.s. (1) \\
\hline \multicolumn{4}{|l|}{ TMJ sounds } \\
\hline Ear noise & $0 \cdot 20^{\star *}(7)$ & 0.07 n.s. (4) & 0.03 n.s. (5) \\
\hline Auscultation & 0.12 n.s. (3) & 0.13 n.s. & 0.11 n.s. (1) \\
\hline
\end{tabular}

Values for Cramér's $V$ are given. Two associations may have the same value but different degree of significance, $n=203$. Missing values are, if $>0$, given within parentheses after the percentage values. ${ }^{*} P<0.05 ; * * P<0.01$; $* * * P<0.001$, n.s. $P>0.05$. The values for Cramér's $V$ are to be interpreted in the following way: 0.00 and under $0.10=$ negligible association; 0.10 and under $0 \cdot 20=$ weak association: $0 \cdot 20$ and under $0 \cdot 40=$ moderate association: 0.40 and under $0 \cdot 60=$ relative strong association. the masseter $(0 \cdot 24)$ and the temporalis areas (0.19); lateral deviation during jaw opening $(0 \cdot 27)$; and reduced opening degree $(0 \cdot 15)$.

\section{Association between CMD variables recorded by interview and by palpation or auscultation}

There were significant associations between each one of the six pain variables recorded by interview (history of pain and pain at function) and each one of the four pain variables recorded by palpation of the TMJ, temporal and masseter areas (Table 4). The association between ear noise and TMJ sounds as recorded by auscultation was negligible (Cramér's $V<0 \cdot 10, P=0 \cdot 09$ ).

\section{Discussion}

The results of this study confirm that parafunctional habits are associated with dysfunction and oral/facial pain (Lindqvist, 1971; Magnusson \& Carlsson, 1978; Egermark-Eriksson, 1982a,b; Lous \& Olesen, 1982;
Nilner, 1983; Westling, 1988) and show that the effects are evident as early as 5 years of age with significant associations also between CMD signs/symptoms and race and sex. Most CMD pain symptoms were associated with the parafunctions, primarily with bruxism, but also with thumb sucking and fingernail biting.

A relatively strong association (Cramér's $V=0.41$ ) was found between bruxism and neck pain. This is of high interest since neck pain is a common cause for sick leave (Kirveskari, 1991). Twenty-two children had palpation pain in the masseter and $2 \mathrm{I}$ children had palpation pain in the temporal area. As with Nilner \& Kopp (1983) and Egermark-Eriksson (1982a), we found tenderness of the temporalis and masseter muscle areas to be significantly correlated to recurrent headache. However, an interesting difference was found between the masseter and temporal areas regarding association with parafunction. The parafunctions were significantly associated with tenderness in the masseter area while the associations with tenderness in the temporalis area were negligible (Table 1),

The results showed that race is an important factor in 
Table 2. Association between CMD signs and symptoms and race and sex

\begin{tabular}{|c|c|c|}
\hline & Race & Sex \\
\hline \multicolumn{3}{|l|}{ Pain history } \\
\hline TMJ pain & $0 \cdot 21^{*}$ & 006 n.s. \\
\hline Headache & 0.12 n.s. & $0 \cdot 25^{\star *}$ \\
\hline Earache & $0-16$ n.s. (1) & 0.08 n.s. (1) \\
\hline Neck pain & $0 \cdot 18^{*}$ & 0.04 n.s. \\
\hline \multicolumn{3}{|l|}{ Pain at function } \\
\hline Chewing & $0 \cdot 33^{\star \star \star}(2)$ & $0 \cdot 14^{\star}(2)$ \\
\hline Jaw opening movement & $0 \cdot 26^{n+k}$ & 0.08 n.s. \\
\hline \multicolumn{3}{|l|}{ Pain at palpation } \\
\hline Lateral TMJ & $0 \cdot 18^{* *}$ & 0.09 n.s. \\
\hline Posterior TMJ & $0 \cdot 20^{\star * *}$ & 0.07 n.s. \\
\hline Masseter & $0 \cdot 21^{\star *}$ & $0.04 \mathrm{n} . \mathrm{s}$. \\
\hline Temporalis & $0 \cdot 18^{* *}$ & 0.01 n.s. \\
\hline \multicolumn{3}{|l|}{ Jaw movement dysfunction } \\
\hline Problems in jaw opening & 0.05 n.s. (1) & 0.04 n.s. (1) \\
\hline Deviation at jaw opening & 0.10 n.s. & 0.04 n.s. \\
\hline Reduced jaw opening degree & 0.08 n.s. & 0.06 n.s. \\
\hline \multicolumn{3}{|l|}{ TMJ sounds } \\
\hline Ear noise & $0.21^{\star \star}(4)$ & $0 \cdot 10$ n.s. (4) \\
\hline Auscultation & $0 \cdot 23^{\text {*** }}$ & $0 \cdot 16^{k}$ \\
\hline
\end{tabular}

Values for Cramér's $V$ are given. Two associations may have the same value but different degree of significance. $n=203$. Missing values are, if $>0$, given within parentheses after the percentage values. * $P<0.05 ; * * P<0.01$; *** $P<0.001$. n.s. $P>0.05$. The values for Cramér's $V$ are to be interpreted in the following way: $0-00$ and under $0 \cdot 10=$ negligible association: $0 \cdot 10$ and under $0 \cdot 20=$ weak association: $0 \cdot 20$ and under $0 \cdot 40=$ moderate association.
Table 3. Association between TMJ sounds and other signs and symptoms of $\mathrm{CMD}$

\begin{tabular}{|c|c|c|}
\hline & Ear noise & $\begin{array}{l}\text { TMJ sounds } \\
\text { at auscultation }\end{array}$ \\
\hline \multicolumn{3}{|l|}{ Pain history } \\
\hline TMJ pain & $0 \cdot 27^{\star \star \star}(4)$ & 0.13 n.s. \\
\hline Headache & 0.02 n.s. (4) & 0.16 n.s. \\
\hline Earache & $0 \cdot 10$ n.s. (5) & $0 \cdot 18^{*}(1)$ \\
\hline Neck pain & $0 \cdot 22^{\star *}(4)$ & 0.04 n.s. \\
\hline \multicolumn{3}{|l|}{ Pain at function } \\
\hline Chewing & $0 \cdot 24^{* * *}(6)$ & 0.13 n.s. (2) \\
\hline Jaw opening & $0 \cdot 20^{\star *}(4)$ & $0 \cdot 16^{*}$ \\
\hline \multicolumn{3}{|l|}{ Palpation tenderness } \\
\hline Lateral TMJ & $0 \cdot 20^{* *}(4)$ & $0 \cdot 30^{* * *}$ \\
\hline Posterior TMJ & 0.13 n.s. (4) & $0 \cdot 30^{\star \star \star *}$ \\
\hline Masseter area & $0 \cdot 23^{\star \star}(4)$ & $0 \cdot 24^{\star * *}$ \\
\hline Temporalis area & 0.12 n.s. (4) & $0 \cdot 19^{\star \star}$ \\
\hline \multicolumn{3}{|l|}{ Jaw movement dysfunction } \\
\hline Problems in jaw opening & 0.11 n.s. (5) & 0.02 n.s. (1) \\
\hline Deviation at jaw opening & 0.11 n.s. (4) & $0 \cdot 27^{\star \star \star}$ \\
\hline Reduced jaw opening degree & 0.02 n.s. (4) & $0.15^{\star}$ \\
\hline
\end{tabular}

The association between ear noise and TMJ sounds was negligible. $n=203$. Missing values are, if $>0$, given within parentheses after the percentage values. ${ }^{*} P<0.05 ;{ }^{* *} P<0.01 ;{ }^{* * *} P<0.001$. a.s. $P>0.05$. The values for Cramér's $V$ are to be interpreted in the following way: $0 \cdot 00$ and under $0 \cdot 10=$ negligible association; $0 \cdot 10$ and under $0 \cdot 20=$ weak association; $0 \cdot 20$ and under $0 \cdot 40=$ moderate association.

the history of CMD (Table 2). Significant associations were found between race and a majority of the pain and dysfunction signs while only a few were associated with sex.

Like Nilner (1983) we found a significant association

\begin{tabular}{|c|c|c|c|c|}
\hline & $\begin{array}{l}\text { Palpation pain } \\
\text { Lateral TMJ }\end{array}$ & Posterior TMJ & Masseter & Temporalis \\
\hline \multicolumn{5}{|l|}{ Pain history } \\
\hline TMJ pain & $0 \cdot 30^{* * *}$ & $0 \cdot 29^{* * *}$ & $0 \cdot 33^{* * *}$ & $0 \cdot 21^{*}$ \\
\hline Headache & $0 \cdot 33^{* * *}$ & $0 \cdot 36^{\star * \star}$ & $0.23^{* *}$ & $0 \cdot 18^{*}$ \\
\hline Earache & $0.32^{* k *}\{1\}$ & $0.31^{* * *}(1)$ & $0 \cdot 35^{* * *}(1)$ & $0 \cdot 23^{* *}(1)$ \\
\hline Neck pain & $0 \cdot 31^{* * *}$ & $0-28^{\star \star \star}(1)$ & $0 \cdot 34^{* * *}$ & $0 \cdot 32^{\star \star \star}$ \\
\hline \multicolumn{5}{|l|}{ Pain at function } \\
\hline Chewing pain & $0.30^{\star \star *}\{2\}$ & $0.31^{\star * *}(2)$ & $0 \cdot 25^{* * *}(2)$ & $0 \cdot 19^{* *}(2)$ \\
\hline Jaw opening pain & $0.42^{\star \star \star}$ & $0 \cdot 41^{\star \star \star}$ & $0.56^{* \star *}$ & $0 \cdot 31^{\star * \star}$ \\
\hline
\end{tabular}

Table 4. Association between pain symptoms of CMD recorded through questionnaires and pain symptoms of CMD obtained by palpation

$n=203$. Missing values are, if $>0$, given within parentheses after the percentage values.

${ }^{*} P<0.05 ;{ }^{* *} P<0.01 ;{ }^{* * *} P<0.001$. n.s. $P>0.05$. The values for Cramér's $V$ are to be interpreted in the following way: 0.00 and under $0 \cdot 10=$ negligible association; $0 \cdot 10$ and under $0.20=$ weak association; 0.20 and under $0.40=$ moderate association; 0.40 and under $0 \cdot 60=$ relatively strong association. 
between TMJ sounds and pain at jaw opening. Most of the CMD signs/symptoms were associated either with ear noise as recorded by interviewing the children and/ or with TMJ sounds as recorded by auscultation (Table 3). There was, however, negligible association between ear noise and TMJ sounds. This indicates that a patient's report of ear noise and the examiner's recording of TMJ sounds should not necessarily be assumed to indicate exactly the same types of disorder or dysfunction. Instead, they may complement each other by giving specific information about different aspects of CMD aiding in differential diagnosis. Furthermore, a subject with ear noise should not automatically be expected to also have TMJ sounds detectable by auscultation, or vice versa. Ear noise is perceived by bone-conduction and, therefore, quite differently by the subject when compared to the sound the examiner may hear. The 'sound event' may occur only a few $\mathrm{mm}$ from the subject's auditory canal and a comparatively long distance, $20-30 \mathrm{~mm}$, from the area where the stethoscope is in contact with the skin. Sound events may also occur close to the skin surface and comparatively far away from the hearing organ.

It has been suggested that recordings of CMD symptoms from children have a relatively low reliability and that questions to 5-year-old children about subjective pain symptoms give too unreliable data (Kirveskari, Alanen \& Järmä, 1986; Rothenberg, 1991). We found, however, significant associations between pain as recorded by questions about pain history and pain at palpation (Table 4). This indicates that interview data from children at such a young age can be reliable enough to include in epidemiological studies.

Some oral parafunctions such as thumb sucking (Ayer, 1979; Rugh \& Lemke, 1984) may gradually disappear during childhood or may persist, like nail biting (Wechsler, 1931) which also has a high prevalence in older age groups (Könönen et al., 1987), or evolve into other destructive behaviours such as cigarette smoking, pipe stem biting, pencil biting etc. It has been shown that dysfunctional oral habits can be eliminated or changed into harmless motor behaviours by appropriate therapeutic procedures including counselling and relaxation training (Maletzky, 1974; deLuca \& Holborn, 1984; Miltenberger \& Fuqua, 1985; Kleinrock et al., 1990). Even if most CMD symptoms in children are mild, there is always a risk that they may develop into higher severity as the child matures, and we agree with those who advocate an early treatment (Stack \&
Funt, 1977; Wänman, 1987). It is important for an appropriate timing of such procedures to find out when early signs of CMD may appear in association with oral parafunctions.

In conclusion, this study demonstrates significant associations between important CMD signs and symptoms and oral parafunctions occurring in youngsters $4-6$ years of age. Regular examinations, screening for signs and symptoms of $\mathrm{CMD}$, and the initiating of prophylactic procedures may therefore be justified with pre-school children. Longitudinal studies, beginning with younger age groups are, however, needed to better evaluate the role in CMD aetiology by childhood oral parafunctions.

\section{Acknowledgments}

The authors want to express their gratitude to Dr Henry Kanar and to Ms Henri M. Parker, R.N. for their help in the arrangements for examining the children.

\section{References}

Asł, M.M. JR (1986) Current concepts in the aetiology, diagnosis and treatment of TMJ and muscle dysfunction. Journal of Oral Rehabilitation, 13, 1.

AYER. W.A. (1979) Oral Motor Behavior: Impact on Oral Conditions and Dental Treatment. P. Bryant, E. Gale, \&. J. Rugh, eds. p. 7-22. U.S. Deparment of Health, Education and Welfare, Bethesda, MD.

BACKLUND, E. (1963) Facial growth and the significance of oral habits, mouthbreathing and soft tissues for malocclusion. Acta Odontologica Scandinavica, 21. Suppl. 36. Thesis.

EGERMARK-ERIKSSON, I. (1982a) Mandibular dysfunction in children and in individuals with dual bite. Swedish Dental Journal. Suppl. 10. Thesis.

Egermark-ERIKsson, I. (1982b) Prevalence of headache in Swedish schoolchildren. Acta Pediatrica Scandinavica, 71, 135.

Franks, A.S.T. (1964) The social character of temporomandibular joint dysfunction. The Dental Practitioner, 15, 94.

GUNN, S.M., WOOLFOLK, M.W. \& FAJA, B.W. (1988) Malocclusion and TMJ symptoms in migrant children. Journal of Craniomandibular Disorders: Facial \& Oral Pain, 2, 196.

Helkimo, M. (1979) Temporomandibular Joint. Function and Dysfunction. G. A. Zarb \& G. E. Carlsson, eds. p. 175-192. Munksgaard, Copenhagen.

Heló, B., Helöe, L. A. \& Heiberg, A. (1977) Relationship between sociomedical factors and TMJ-symptoms in Norwegians with myofascial pain-dysfunction syndrome. Community Dentistry and Oral Epidemiology, 5, 207.

KIRVESKARI, P. (1991) Are craniomandibular disorders a general health problem? Proceedings of the Finnish Dental Society, 87, 309.

KiRVESKARI, P., AlANEN, P. \& JÄMSÁ, T. (1986) Functional state of the stomatognathic system in 5,10 and 15 year old children in 
southwestern Finland. Proceedings of the Finnish Dental Society, $\mathbf{8 2}, 3$.

Kleinrock, M., Mielnick-HuS, J., ZYSKO-WOZNLAK, D., KACZMAREK, A., DORACZYNSKA, E. \& Prc, K. (1990) investigations on prevalence and treatment of fingernail biting. The Journal of Craniomandibular Practice, 8, 47.

Kononen, M., Kleemola-Kujala, E., Kataja, M., Evalaht, M., LAINE, P. \& PECK, L. (1987) Signs and symptoms of craniomandibular disorders in a series of Finnish children. Acta Odontologica Scandinavica, 45, 109.

LindQvist, B. (1971) Bruxism in children. Odontologisk Revy, 22, 413.

Lous, I. \& OLESEN, J. (1982) Evaluation of pericranial tenderness and oral function in patients with common migraine, muscle contraction headache and 'combination headache'. Pain, 12. 385.

DELUCA, R.V. \& HOLBORN, S.W. (1984) A comparison of relaxation training and competing response training to eliminate hair pulling and nail biting. Journal of Behavioural Therapy and Experimenal Psychiaty, 15, 67.

MAgnusson, T. \& CARLSSON. G.E. (1978) Recurrent headaches in relation to temporomandibular joint pain-dysfunction. Acta Odontologica Scandinavica, 36, 333.

MALETZKY, B.M. (1974) Behavior recording as treatment. A brief note. Behavioural Therapy, 5, 107

Miltenberger, R.G. \& FuQuA, R.W. (1985) A comparison of contingent vs. non-contingent competing response practice in the treatment of nervous habits. Journal of Behavioural Therapy and Experimental Psychiatry, 16, 195.

Nin.Ner, M. (1983) Relationships between oral parafunctions and functional disturbances and diseases of the stomathognathic system among children aged 7-14 years. Acta Odonotologica Scandinavica, 41, 167.

NiLnER, M. \& KOPP, S. (1983) Distribution by age and sex of functional disturbances and diseases of the stomatognathic system in 7-18 year olds. Swedish Dental Journal, 7, 191 .

NILNeR, M. \& LASSING, S.A. (1981) Prevalence of functional disturbances and diseases of the stomatognathic system in 7-14 years olds. Swedish Dental Journal, 5, 173.

Poister, T.H. (1978) Public Program Analysis, p. 443. University Park Press, Baltimore.

REA, L.M. \& PARKER, R.A. (1992) Designing and Conducting Sunvy Research, p. 202-204. Jossey-Bass Publishers, San Fransisco.

ROTHENBERG, L.H. (1991) An analysis of maximum mandibular movements, craniofacial relationships and temporomandibular joint awareness in children. The Angle Orthodontist, 61, 103.

Rugh, J.D. \& LEMKE, R.R. (1984) Social Sciences and Dentistry. A Critical Bibliography. Vol. II. p. 19-83. Cohan \&. Bryant, eds. Quintessence, London.

STACK, B.C. \& FUNT, L.A. (1977) Temporomandibular joint dysfunction in children. Sournat of Pedodontics, 1, 240.

Thilander, B. (1986) Orthodontics. State of the Art. Essence of the Science, p. 342. L. W. Graber, ed. Mosby, St. Louis.

WANMAN, A. $\{1987\}$ Craniomandibular disorders in adolescents. Swedish Dental Journal, Suppl. 44, p. 32-33. Thesis.

WECHSLER, D. (1931) The incidence and significance of fingernail biting in children. Psychoanalytical Review, 18, 201.

WESTLING, L. (1988) Fingernail biting: a literature review and case reports. The Journal of Craniomandibular Practice, 6, 182.

Widmalm, S.E., Christiansen, R.L., Gunn, S.M. \& Hawley, L.M. (1995) Prevalence of signs and symptoms of craniomandibular disorders and orofacial parafunction in 4-6 year-old-AfricanAmerican and Caucasian children. Journal of Oral Rehabilitation, 22. 87 .

Correspondence: Dr Sven E. Widmalm, 1565 Kuehnle, Ann Arbor, M1 48103, U.S.A. 
This document is a scanned copy of a printed document. No warranty is given about the accuracy of the copy. Users should refer to the original published version of the material. 